\title{
Assistência às vítimas de acidente de trânsito: percepções da equipe de resgate móvel
}

\author{
Aldaíza Ferreira Antunes Fortes, M.Sc.*, Marcela Rodrigues Souto Prado**, Renata de Castro Matias***
}

${ }^{*}$ Enfermeira, Docente da disciplina Estágio Supervisionado da Administração da Assistência de Enfermagem e Estágio Supervisionado em Gerenciamento de Enfermagem, do Curso de Graduaçáo em Enfermagem da Escola de Enfermagem Wenceslau Braz (EEWB), Responsável pelo Setor de Pesquisa e Estudos Acadêmicos da EEWB, **Enfermeira, Especialista em Urgência e Emergência, pela EEWB, Enfermeira da Clinica Médica do Hospital Escola, de Itajubá, ${ }^{* * *}$ Enfermeira, Especialista em Urgência e Emergência, pela EEWB, Docente assistente das Disciplinas Estágio Supervisionado da Administração da Assistência de Enfermagem e Estágio Supervisionado em Gerenciamento de Enfermagem, do Curso de Graduação em Enfermagem da EEWB, Coordenadora da Comissão Própria de Avaliação da EEWB

\section{Resumo}

Estudo de abordagem quanti-qualitativa, do tipo exploratório-descritivo e transversal, realizado no período de maio a junho de 2011, com o objetivo de identificar as percepçôes dos socorristas atuantes no Atendimento Pré Hospitalar Móvel da Autopista Fernão Dias, nas bases operacionais 3 e 4, acerca do trabalho que desenvolvem com seus colegas ao assistirem vítimas de acidente de trânsito. A amostra foi constituída por doze socorristas da Autopista Fernão Dias. O tipo de amostragem foi intencional. Da análise dos dados, à luz de Bardin, verificou-se que 41,66\% referem que o trabalho desenvolvido é de remoçáo da vítima estabilizada para o pronto socorro mais próximo, unido e em equipe, estando diretamente relacionado com o cumprimento do papel de cada profissional e o auxílio ao colega no que for necessário. Não houve homogeneidade nas opinióes acerca do trabalho desenvolvido por eles, ou seja, 50\% informaram que não há necessidade de alterar a forma de trabalho e outros $50 \%$ referiram que o trabalho poderia ser desenvolvido de outra forma, oferecendo sugestóes de melhoria para o trabalho.

Palavras-chave: socorristas, assistência pré-hospitalar, emergências.

\section{Abstract}

\section{First aid to traffic accident victims: perceptions of mobile paramedic team}

This is a quantitative and qualitative study with exploratory-descriptive and cross-sectional approach, conducted from May to June 2011 aiming at identifying the perceptions of mobile paramedic team of Prehospital Care Mobile of Fernão Dias Road, operational bases 3 and 4, in relation to the work performed together with their colleagues to help traffic accident victims. The sample consisted of twelve paramedic of Fernão Dias Road. It was an intentional sampling method. Data was analyzed according to Bardin and we verified that $41.66 \%$ mentioned that the team's work consisted in removing the stabilized victim 
to the nearest emergency hospital, being directly related to fulfill their role and support their colleagues work when needed. There was no uniformity in opinions regarding their work, as 50\% reported that there is no need to change the way they work and another $50 \%$ reported that the work could be managed in different ways, offering work improvement suggestions.

Key-words: emergency responders, prehospital care, emergencies.

\section{Resumen}

\section{Atención a las víctimas de accidentes de tráfico: percepciones del equipo de rescate móvil}

Este estudio cuantitativo y cualitativo que utilizó el método exploratorio-descriptivo y transversal fue realizado entre mayo y junio de 2011 con el objetivo de identificar las percepciones de los equipos de rescate en Atención Prehospitalaria Móvil de la Autopista Fernáo Dias, en las bases operativas 3 y 4, acerca del trabajo que desarrollan con sus compañeros para atender a las víctimas de accidente de tráfico. La muestra fue constituida de doce socorristas de la autopista Fernáo Dias. El tipo de muestreo fue intencional. El análisis de los datos, de acuerdo con Bardin, verificó que 41,66\% reportaron que el trabajo consiste en manejar la víctima inmovilizada para Hospitales de Emergencias más cercanos y mantener el equipo unido, cumpliendo cada profesional su papel y ayudar sus compañeros cuando sea necesario. No hubo uniformidad en las opiniones sobre el trabajo realizado por ellos, es decir, el 50\% relataron que no había necesidad de cambiar la forma de trabajar y los otros 50\% que el trabajo se puede desarrollar de otra manera, ofreciendo propuestas de mejora.

Palabras-clave: socorristas, atención prehospitalaria, emergencias.

\section{Introdução}

O Atendimento Pré Hospitalar Móvel de Autopista (APHM) é uma modalidade de assistência especializada, fora do ambiente hospitalar, cuja finalidade de atendimento visa à manutenção da vida e/ou a minimização das sequelas. Procura ter acesso à vítima nos primeiros minutos após ter ocorrido o agravo à sua saúde, sendo necessária, a prestação de atendimento adequado e transporte a um hospital devidamente hierarquizado e integrado ao Sistema Único de Saúde (SUS) [1].

A finalidade do APHM, como um serviço de saúde, é possibilitar a cura, o restabelecimento do paciente e, na situação especifica do acidente de trânsito, salvar a vida das vítimas, mantê-las vivas até a chegada ao local onde será possível curá-las ou diminuir as sequelas, possibilitando uma melhor qualidade de vida. A partir dessa finalidade é que o serviço se organiza e determina o objetivo específico dessa instância do sistema de saúde, que é caracterizado por um atendimento rápido, estabilização da vítima no local do evento, imobilizaçáo adequada e transporte ao hospital de referência em condiçóes viáveis ao tratamento definitivo [2].

O crescimento de serviços de APHM tem por razão o aumento de vítimas de acidentes com traumas como resultados do próprio avanço científico e tecnológico [1]. Este crescimento também é considerado reflexo do número de veículos em circulaçáo, da desorganização do trânsito, da deficiência geral da fiscalização, das condiçôes dos veículos, do comportamento dos usuários e da impunidade dos infratores [3].

Os profissionais do APHM quando atendem uma vítima de acidente de trânsito tem como meta a garantia da vida do paciente até a chegada ao local de tratamento. Sabe-se que o tempo para cumprir esse objetivo é mínimo, fazendo-se necessário o trabalho em equipe, gerando relaçóes de complementaridade de conhecimentos e habilidades, otimizando assim a assistência e tornando-a organizada e de qualidade.

$\mathrm{Na}$ prática cotidiana dos serviços de APHM, o trabalho é alicerçado a partir de instrumentos tecnológicos e do estabelecimento de relaçóes entre os atores, especialmente no atendimento à vítima de acidentes de trânsito, quando várias áreas se envolvem nessa assistência. $\mathrm{O}$ trabalho desenvolvido caracteriza-se como um trabalho coletivo, cujo resultado depende dos atos de cada um desses atores, que atuam de acordo com seus saberes e práticas específicas, e por todos eles no seu conjunto. As ações são desenvolvidas por vários profissionais, respeitadas as especificidades, competências e responsabilidades de cada membro da equipe [4].

A equipe de saúde realiza no APHM um trabalho integrado, que garante a qualidade e agilidade na assistência prestada às vitimas. É necessária 
uma sintonia, um entendimento entre os membros da equipe, que transcende a relação hierárquica historicamente encontrada nas organizaçôes de saúde. Nesse momento, as relaçóes estabelecidas são horizontais, proporcionando a realização de açóes conjuntas que possibilitam a realização de um atendimento rápido e adequado [4].

Após estas consideraçôes, apresentamos como pergunta de pesquisa: o que os socorristas atuantes no APHM pensam a respeito do trabalho que desenvolvem com seus colegas no atendimento a vítimas de acidente de trânsito?

É importante estar atento a essas questóes que de uma maneira ou de outra influenciam diretamente na assistência prestada à vítima e no seu prognóstico.

Ante o exposto, o presente estudo teve como objetivo identificar as percepçóes dos socorristas atuantes no APHM da Autopista Fernão Dias, nas bases operacionais 3 (Camanducaia) e 4 (Pouso Alegre), acerca do trabalho que desenvolvem com seus colegas ao assistirem vítimas de acidente de trânsito.

\section{Material e métodos}

Trata-se de uma pesquisa de abordagem quanti-qualitativa, do tipo exploratório-descritiva e transversal, realizada com doze socorristas atuantes no APHM da Autopista Fernão Dias, nas bases operacionais 3 e 4 das cidades de Camanducaia e Pouso Alegre respectivamente, Minas Gerais, que assistem vítimas de acidente de trânsito.

O tipo de amostragem foi intencional. Iniciamos a coleta de dados somente após a aprovação, do Comitê de Ética em Pesquisa, da Escola de Enfermagem Wenceslau Braz, conforme parecer consubstanciado no 433/2011. Ela ocorreu por meio de um roteiro de entrevista semiestruturada, composto por duas partes sendo a primeira referente ao perfil sócio demográfico dos participantes e, a segunda contendo duas questóes abertas relacionadas com o objetivo do estudo.

Antes da utilização definitiva, destes instrumentos, foi realizado um pré-teste, com três socorristas atuantes no APHM da Autopista Fernáo Dias nas bases operacionais 3 e 4 , sendo eles incluídos na amostra deste estudo.

O pré-teste serviu para identificar três importantes elementos: fidedignidade, validade e operatividade [5]. Após sua realização, averiguamos que não havia necessidade de alteração das duas questóes abertas do segundo instrumento para coleta de dados.

As entrevistas ocorreram no período de maio a junho de 2011, e foram gravadas em fitas cassetes, as quais, após a transcrição dos dados, foram destruídas de forma a não agredir o meio ambiente.

Os dados coletados foram transcritos conforme os critérios metodológicos, permitindo a fidedignidade das informaçóes colhidas. Em seguida, os referentes às duas questóes abertas foram analisados e interpretados por meio da análise do conteúdo de Bardin [6]. Já os inerentes ao perfil sociodemográfico dos participantes foram analisados à luz da estatística descritiva.

A análise de conteúdo de Bardin é a técnica mais difundida, para investigar o conteúdo das comunicaçôes, mediante a classificação, em categorias, dos elementos da comunicação. Consiste na descoberta dos núcleos de sentido que compóem uma comunicaçáo, de forma que a presença ou frequência seja significativa, para o objetivo analítico visado [6].

Preservou-se a confidencialidade e o anonimato de todos os participantes da pesquisa, utilizando a codificação S1 para socorrista um, S2 para socorrista dois e, assim por diante, conforme o número de entrevistados.

Durante todas as etapas do estudo, foram atendidas, criteriosamente, as recomendaçôes expressas na Resolução No. 196/96, do Conselho Nacional de Saúde, concernentes à realizaçáo de pesquisas com seres humanos [7].

\section{Resultados e discussão}

Em relação ao perfil sócio demográfico dos participantes da pesquisa, nove pertenciam ao gênero masculino e três ao gênero feminino, este fato é justificável por este serviço em especial demandar força física, que na maioria das vezes é necessária ao atendimento e remoção das vítimas. (Tabela I).

Quanto à profissão, sete eram motoristas/socorristas, três eram enfermeiros e dois eram médicos. Em relação à religião, dez eram católicos, um referia acreditar em Deus e o outro dizia náo ter religião.

Como pode ser observado na tabela II, houve variação entre as idades, sendo que a faixa etária oscilou de 20 a 45 anos e a idade média foi de 31,5 anos, com desvio padrão (DP) de mais ou menos 7,36 anos, já a moda foi de 28 anos. Um serviço desta natureza requer presença de pessoas jovens e ágeis, pois a idade é um fator que intervém posi- 
tivamente na qualidade da assistência prestada na urgência [8].

A Tabela II também apresenta o tempo de atuação dos entrevistados. A média de atuação foi de 1,47 anos e o desvio padrão (DP) de mais ou menos 0,95 anos, sendo a moda de 0,5 anos, ou seja, 6 meses. $\mathrm{O}$ valor da moda deve ser levado em consideração, pois a não manutenção da equipe é vista por alguns entrevistados como algo ainda a ser melhorado no serviço.

Tabela I - Características pessoais e profissionais dos socorristas da Autopista Fernão Dias. Camanducaia e Pouso Alegre/MG, 2011.

\begin{tabular}{lcc}
\hline \multicolumn{1}{c}{ Variável } & $\begin{array}{c}\text { Frequência } \\
\text { absoluta }\end{array}$ & $\begin{array}{c}\text { Frequência } \\
\text { relativa }\end{array}$ \\
\hline Gênero: & 9 & $75 \%$ \\
Masculino & 3 & $25 \%$ \\
Feminino & & \\
Situação Religiosa: & 10 & $83,33 \%$ \\
Católico & 1 & $8,33 \%$ \\
Acredita em Deus & 1 & $8,33 \%$ \\
Não pratica religião & & \\
Profissão: & 7 & $58,33 \%$ \\
Motorista socorrista & 3 & $25 \%$ \\
Enfermeiro & 2 & $16,66 \%$ \\
Médico &
\end{tabular}

Fonte: Instrumento de Pesquisa $(n=12)$.

Ao analisarmos os dados da primeira questão aberta "Fale para mim, como é o trabalho que você e seus colegas desenvolvem no APHM ao assistirem vítimas de acidentes de trânsito?” evidenciamos 9 categorias: "de remoção da vítima estabilizada para o PS mais próximo"; "unido e em equipe"; "de responsabilidade"; "bem feito"; "de aplicação do protocolo de trauma da empresa"; "de manutenção da segurança da equipe"; "de transmissão de calma no momento do atendimento"; "de utilização de uma linguagem acessivel à vítima"; "Importante, arriscado e pouco valorizado".
$\mathrm{Na}$ categoria, de remoção da vítima estabilizada para o PS mais próximo, podemos perceber que cinco socorristas, ou seja, $41,66 \%$ dos entrevistados sabem que o APHM é uma modalidade de atendimento prestado fora do ambiente hospitalar, cuja finalidade de atendimento visa à manutenção da vida e/ou minimização de sequelas.

Isso é sinalizado nos seguintes depoimentos:

“[...] O nosso trabalho no APH móvel é fazer o necessário para remover a vítima estabilizada e com vida para o Pronto Socorro mais próximo [...]."(S1).

“[...] tentar minimizar as lesóes relacionadas ao trauma encaminhando a vítima da maneira mais estável possível ao intra-hospitalar." (S10).

A equipe de Suporte Avançado de Vida no APHM é composta de motorista, médico e enfermeiro, e se caracteriza por oferecer atendimento às pessoas em situaçóes de urgência ou emergência no próprio local da ocorrência do evento, garantindo um atendimento precoce. Para que a equipe possa garantir um bom atendimento é primordial a chegada rápida até a vítima, a análise da cena do agravo e a identificação dos possíveis riscos à equipe e à vítima, e o restabelecimento das funçóes vitais e encaminhamento para o atendimento intra-hospitalar [9].

Observamos na categoria, unido e em equipe, que cinco socorristas $(41,66 \%)$ enfatizam que cada profissional deve realizar seu papel e ajudar o colega no que ele precisa durante o atendimento à vítima para que no final seja alcançado o objetivo de prestar a assistência com qualidade e eficiência, como demonstram os relatos:

"[...] trabalho com médico e enfermeiro [...] sinalizo o local para proteger a equipe e a vítima, e entrego todo o material que

Tabela II - Medidas de tendência central da idade e do tempo de atuação no serviço dos socorristas da Autopista Fernão Dias. Camanducaia e Pouso Alegre/MG, 2011.

\begin{tabular}{lcccccc}
\hline \multicolumn{1}{c}{ Variáveis } & Média & Mediana & $\begin{array}{c}\text { Desvio } \\
\text { Padrão }\end{array}$ & $\begin{array}{c}\text { Valor Míni- } \\
\text { mo }\end{array}$ & $\begin{array}{c}\text { Valor } \\
\text { Máximo }\end{array}$ & Amplitude \\
\hline $\begin{array}{l}\text { Idade (anos) } \\
\begin{array}{l}\text { Tempo de atuação no } \\
\text { APHM da Autopista }\end{array}\end{array}$ & 31,5 & 28 & 7,36 & 20 & 45 & 25 \\
\begin{tabular}{l} 
Fernão Dias (anos) \\
\hline
\end{tabular} & 1,47 & 1,55 & 0,95 & 0,5 & 3 & 2,5 \\
\hline
\end{tabular}

Fonte: Instrumento de Pesquisa $(\mathrm{n}=12)$. 
eles necessitam [...] O trabalho tem que ser realizado em equipe para dar atendimento com sucesso." (S5).

“[...] A grande importância é o trabalho em equipe, pois a gente não resolve nada sozinho. A equipe não se separa a gente não pode perder o contato, porque um depende do outro [...]." (S6).

No APHM o trabalho em equipe é crucial, pois as atividades são fundamentadas no coletivo, haja vista que as situaçôes vivenciadas pelos profissionais atuantes nesse serviço são sempre de emergência [10]. Percebemos com isto que a ação do profissional de saúde não se dissocia da interação, pois se trata de um instrumento básico no processo que torna possível o relacionamento entre os integrantes da equipe.

Examinando a categoria, de responsabilidade, evidenciamos que quatro entrevistados $(33,33 \%)$ afirmam que ao prestar assistência à vítima de acidente de trânsito desenvolvem um trabalho de responsabilidade, principalmente no que se refere em assumir responsabilidades individuais e promover a segurança do grupo e vítima:

"[...] cada um tem que assumir a sua responsabilidade dentro da equipe [...].” (S2).

"[...] Chegando ao local indicado utilizamos os três ' $S$ ' cena, situação e segurança, principalmente segurança da equipe e da vítima, só quando a cena esta segura agente atende a vítima $[\ldots] "$ ".. (S6).

No cenário do APHM, é imperativo que os profissionais tenham formação polivalente e orientada para a visão da realidade. Daí a importância de se trabalhar a partir da definição de áreas de competência, possibilitando a integração de diferentes saberes e conhecimentos e a interaçáo multiprofissional, contribuindo para a formação de um profissional que agregue aptidóes para a tomada de decisóes, comunicação, liderança e gerenciamento. Essas devem ser as características e responsabilidades do profissional que atua no ambiente pré-hospitalar, pois permanentemente se depara com situaçôes que exigem aptidôes, além do conhecimento técnico [9].

Interpretando a categoria, bem feito, verificamos que apenas um socorrista $(8,33 \%)$ referiu que para lograr êxito no atendimento é necessária a soma de esforços individuais para culminar em um trabalho em equipe e bem feito:

[...] depende do trabalho individual [...] para no final o trabalho sair em equipe e bem feito." (S2).

Existem três áreas que atuam em um $\mathrm{APH}$, sendo elas: Médica, Enfermagem e Condutores socorristas, cada uma trabalha em cima de uma competência de atuação em que uma se integra à outra com um só objetivo, o desfecho do agravo. $\mathrm{O}$ sucesso do atendimento, ou seja, para o serviço ser executado de forma eficaz, depende em sua maioria do empenho e sincronismo de toda esta equipe de trabalho [10].

$\mathrm{Na}$ categoria, de aplicação do protocolo de trauma da empresa, constatamos que a utilização do protocolo foi mencionada por três socorristas (25\%). Compreendemos que o uso do protocolo na assistência ao traumatizado é extremamente importante, pois com a criação e correta utilização do mesmo é garantida uma padronização da assistência ao trauma. O protocolo é uma forma de sistematizar a assistência prestada, provê maior respaldo teórico, e qualifica o atendimento:

$$
\begin{aligned}
& \text { "Desenvolvemos o protocolo de Trauma } \\
& \text { criado pela empresa [...]" (S7). } \\
& \text { “[...] respeitando o protocolo de Segurança } \\
& \text { e de Atendimento do Trauma da Empresa } \\
& \text { [...]." (S8). }
\end{aligned}
$$

Os protocolos de atendimento no APH proporcionam objeto de consulta para os profissionais atuantes e colaboradores recém-admitidos no serviço. É imprescindivel que as unidades elaborem e tenham homologados os protocolos para a fundamentação das açóes dos estabelecimentos de saúde e amparo legal daqueles que executam açôes nele [11].

Compreendendo a categoria de manutenção da segurança da equipe, notamos que $25 \%$ dos socorristas enfatizam que ao executar o atendimento a vítimas de acidente de trânsito, priorizam a manutenção da segurança da equipe. Ao chegar ao local do acidente, a primeira responsabilidade da equipe de resgate é garantir sua própria segurança, logo deve ser avaliado a cena, situação e segurança. $\mathrm{O}$ condutor/socorrista sinaliza toda área para que o médico 
e o enfermeiro possam prestar assistência direta à vítima com segurança, já que prestam atendimento nos mais diversos locais de risco:

"Em primeiro lugar preconizamos a segurança da equipe [...].” (S8).

"Primeiramente visamos à segurança da equipe $[\ldots] . "(S 12)$.

Toda pessoa que estiver realizando o atendimento de primeiros socorros deve, antes de tudo, atentar para a sua própria segurança. $\mathrm{O}$ impulso de ajudar as outras pessoas não justifica a tomada de atitudes inconsequentes, que acabam transformando-o em mais uma vítima [12].

$\mathrm{Na}$ categoria de transmissão de calma no momento do atendimento podemos perceber que dois socorristas $(16,66 \%)$ ressaltaram que na prestação de assistência à vítima a calma deve ser mantida, com o intuito de garantir um socorro eficaz, como demonstram os relatos:

"A primeira coisa que a gente tem que fazer é passar calma no momento do atendimento [...]." (S9)

"[...] posterior o atendimento a vítima, mantendo a calma, sem afobação [...].” (S12)

Cabe ao profissional de APH ser preciso, aproximar-se do perfeito, ter uma postura calma e firme, estar consciente de sua escolha profissional e utilizar todo o seu conhecimento e humanismo para prestar o atendimento [13].

Interpretando a categoria de utilização de uma linguagem acessivel à vítima evidenciamos que apenas um entrevistado (8,33\%) afirma que ao assistir uma vítima há a necessidade de utilizar uma linguagem acessível à vítima:

\section{“[...] estar desenvolvendo técnicas ou algu- ma coisa assim para poder estar falando da maneira que a pessoa quer escutar. $\mathrm{Na}$ hora do acidente não tem como estar falando uma linguagem técnica, tem que ser mais simples possível para pessoa entender.” (S9).}

A informação em saúde necessita ser clara, compreensível, recordável, credível, consistente ao longo do tempo, baseada na evidência e personali- zada. Esta personalização significa que a informação é “à medida” das necessidades de informação do profissional e da vítima naquele momento, adaptada ao seu nível cultural e adaptada ao seu estilo cognitivo [14].

Vale mencionar que o profissional deve manter um vínculo de confiança por meio das linguagens verbal e não verbal, pois a vítima percebe seu estado e sua chance, às vezes, por um olhar mais preocupado lançado pelo profissional, sua entonação de voz ou sua expressão facial [15].

$\mathrm{Na}$ categoria importante, arriscado e pouco valorizado notamos que um socorrista $(8,33 \%)$ considera que o trabalho que desenvolve com seus colegas ao atender vítimas de trânsito é importante, arriscado e pouco valorizado. Isso é descrito na fala a seguir:

\footnotetext{
"Pra mim é um trabalho importante que a gente desenvolve de assistência das vítimas e eu acho que deveria ser mais valorizado não só pela importância, mas também pelo risco que a gente corre na rodovia [...].” (S11).
}

Apesar de ser evidenciado em apenas uma fala, o risco de acidente no APHM é o mais elevado, devido ao cenário em que os profissionais estão inseridos, diferenciando-se do sistema hospitalar, o qual é estrategicamente programado para receber seus clientes e são auxiliados por programas que proporcionam um ambiente mais propício e seguro ao atendimento. $\mathrm{O}$ profissional inserido nesse segmento depara-se com as mais diferentes e complicadas situaçóes, como realizar atendimentos em ribanceiras e/ou autoestradas, intempéries e múltiplas vítimas [1].

Ao analisarmos as respostas dos participantes referentes à segunda questão aberta: "Você acha que este trabalho pode ser desenvolvido de outra forma? Por quê?" verificamos que $50 \%$ responderam não, ou seja, que o trabalho desenvolvido por eles na assistência a vítimas de acidentes de trânsito não necessita de alteraçóes e 50\% responderam sim, ou seja, que o trabalho pode ser desenvolvido de outra forma, propondo sugestóes de melhora.

Da análise das justificativas dos participantes que responderam não, emergiram as seguintes categorias: 1) Há entrosamento das equipes; 2) $\mathrm{O}$ trabalho é bem desenvolvido;

A categoria há entrosamento das equipes, elucida a importância dada por dois participantes $(16,66 \%)$ 
ao entrosamento e cooperação dos colegas, como nos mostra as falas:

"Eu acho que não, porque as equipes estáo bem entrosadas." (S3).

"Não, tá muito bom assim, o treinamento que as enfermeiras passam para gente e a experiência do pessoal mais antigo dá para trabalhar durante a ocorrência." (S5).

Muitas vezes, os procedimentos no $\mathrm{APH}$ são realizados concomitantemente, e cada um executa uma tarefa, tornando o atendimento ágil e rápido. Esse tipo de integração tem sido descrito nas situaçóes de emergência sendo necessário realizar açóes de forma articulada, em que os profissionais agem de forma cooperativa, sintonizada e precisa. Essas intervençôes configuram um trabalho coletivo no qual, dada à gravidade da situação, está presente a cooperaçáo, a cumplicidade e a solidariedade entre os profissionais envolvidos [4].

Analisando a categoria o trabalho é bem desenvolvido notamos que quatro participantes (33,33\%) demonstraram estarem satisfeitos com o trabalho desenvolvido por eles ao assistirem vítimas de acidente de trânsito. Essa categoria é percebida nos seguintes relatos:

\footnotetext{
"No momento eu acho que este trabalho está sendo bem desenvolvido e com o decorrer do tempo vamos tentando descobrir se tem outra forma para melhorar o atendimento." (S4).

"Não porque é desenvolvido com estudos internacionais que demonstram que é a maneira mais eficaz e menos prejudicial às vítimas de politrauma." (S10).
}

Este cenário do APHM encontra respaldo em estudos internacionais, os quais sugerem que o atendimento, quando adequado, no ambiente pré-hospitalar diminui a mortalidade dos pacientes vítimas de trauma. Vale ressaltar que em situaçóes de trauma o tempo é essencial e, nesses estudos, verificou-se que quanto mais tempo é gasto na cena, realizando procedimentos avançados, mais tardiamente o paciente recebe o atendimento definitivo, tendo, consequentemente, os piores resultados [2].
Ao analisarmos as respostas dos $50 \%$ dos participantes que disseram sim, ou seja, que o trabalho desenvolvido por eles, em suas opinióes, pode ocorrer de outra forma, averiguamos que eles propuseram sugestóes para melhoria deste trabalho. Desta análise surgiram as seguintes categorias:

1) Não há manutenção da equipe;

2) O saber nunca é o bastante;

3) Há falhas na comunicação.

Por meio destas categorias emergiram algumas sugestóes de melhoria do serviço na Autopista Fernão Dias dadas pelos participantes da pesquisa como: Educação continuada e treinamento; trabalhar com equipe mais especializada, como por exemplo, médicos e enfermeiros especializados em urgência e emergência; criação de cursos voltados para a segurança neste serviço; realizar simulados de atendimento, para preparar os profissionais antes de uma ocorrência real; melhorar o sistema de filmagem (câmeras) da rodovia para facilitar o serviço dos funcionários da central de regulação responsáveis pela transmissão das informações referente ao acidente; Realizar discussôes sobre os casos/ocorrências já vivenciadas pelo grupo.

$\mathrm{Na}$ análise da categoria não há manutenção da equipe notamos que $25 \%$ dos socorristas, afirmam que o ideal para desenvolver as atividades seria a manutenção da equipe, com o intuito de não ocorrer capacitaçóes sem necessidade e o processo contínuo de criação de vínculo:

"Às vezes a gente tem alguns problemas com relação à mudança de equipe [...] às vezes, quando agente está acostumando com a equipe aí tem que sair ou muda de cidade ou de emprego, alta rotatividade dentro do resgate [...]”. (S2).

“[...] a gente sempre pensa em trabalhar com
a mesma equipe, só que quando muda zera
tudo, tem que iniciar um novo treinamento,
criar um novo vínculo, tem que conhecer
cada pessoa e suas atitudes. [...] então o
correto seria não ter rotatividade [...].” (S6)

Entendemos que esta situação vivenciada pelos participantes do estudo reflete diretamente na qualidade do serviço prestado às vítimas.

A rotatividade dentro do APHM rodoviário é muito grande devido à incompatibilidade salarial, pois a maioria dos serviços é terceirizada. Esses serviços na maioria das vezes não investem 
adequadamente em recursos materiais e humanos qualificados [13].

Nesta categoria a sugestão foi um aumento da educaçáo continuada e treinamento. Analisando o tipo de serviço prestado pelos profissionais do APHM da Autopista Fernão Dias e a sugestáo de educação continuada, detectamos que as tensões sofridas por estes profissionais podem ser trabalhadas e minimizadas por intermédio de educaçôes continuadas. A educaçáo continuada proporciona, aos profissionais em questáo, a apropriação de conhecimentos práticos e teóricos, garantindo a eles um melhor enfrentamento das tensóes geradas pelo serviço.

Analisando a categoria o saber nunca é o bastante, percebemos que um participante $(8,33 \%)$ referiu que o saber nunca é o bastante.

"Acho que o saber nunca é o bastante, acho interessante criarem mais cursos de segurança, realizando simulados [...].” (S8).

Podemos afirmar com a fala deste participante que à medida que o profissional do APHM incorpora conhecimentos sobre esta temática percebe que ainda necessita de mais conhecimentos, ou seja, quanto maior o conhecimento maior a necessidade de conhecer ainda mais.

Quanto à sugestão do respondente sobre a criaçáo de cursos e simulados, constatamos que as emergências devem ser analisadas previamente para que decisóes críticas sejam executadas de modo automático no momento da ocorrência. Os profissionais do APHM possuem a responsabilidade pela tomada de decisóes e por esta razáo devem ser adequadamente treinados, pois a possibilidade de cometerem falhas em situaçôes de emergências é muito grande [16].

$\mathrm{Na}$ análise da categoria há falhas na comunicação verificamos que dois socorristas $(16,66 \%)$ afirmaram que a comunicação é algo a ser melhorada em suas atuaçôes:

"Eu acho que sim, principalmente as câmeras deveriam ajudar na situação da cena e estar dando a resposta mais fácil para quem está transmitindo a ocorrência [...] comunicação também, hoje, é escassa futuramente pode ser melhorado." (S9).
“[...] discutir mais as ocorrências [...] essa discussão das ocorrências, casos, acho que isso seria bom para correçáo de erros, para conhecimento de novos protocolos, pelo menos estar por dentro de coisas novas, mesmo que agente não utilize." (S11).

As características e o ambiente do APHM exigem protocolos de atendimentos a serem seguidos. As discussóes com a equipe que participou da ocorrência devem acontecer de forma sistemática, sempre que oportuno, para detecção e correção de comportamentos inadequados, pois o serviço exige tomadas de decisóes que colocam em risco o que há de mais valioso: a vida [16].

De acordo com o objetivo da pesquisa "conhecer as percepçóes dos socorristas atuantes no atendimento pré-hospitalar móvel, da Autopista Fernão Dias das bases operacionais 3 e 4 das cidades de Camanducaia e Pouso Alegre, MG, acerca do trabalho que desenvolvem com seus colegas ao assistirem vítimas de acidente de trânsito", chegou-se as seguintes conclusôes:

As percepçóes desses profissionais foram evidenciadas por meio de nove categorias originadas da primeira questão aberta "fale para mim, como é o trabalho que você e seus colegas desenvolvem no APHM ao assistirem vitimas de acidentes de trânsito?": "de remoção da vítima estabilizada para o PS mais próximo"; "unido e em equipe"; "de responsabilidade"; "bem feito"; "de aplicação do protocolo de trauma da empresa"; "de manutenção da segurança da equipe"; "de transmissáo de calma no momento do atendimento"; "de utilização de uma linguagem acessivel à vitima"; "Importante, arriscado e pouco valorizado". Em relaçáo à segunda questão aberta "você acha que este trabalho pode ser desenvolvido de outra forma? Por quê?", as categorias elucidadas foram divididas em: Categorias que referem que o trabalho pode ser desenvolvido de outra forma: "Não há manutenção da equipe", "O saber nunca é o bastante" e "há falhas na comunicação"; e Categorias que referem que o trabalho náo precisa ser desenvolvido de outra forma: Há entrosamento das equipes" e "O trabalho é bem desenvolvido".

No que se refere ao trabalho desenvolvido pelos socorristas e seus colegas ao assistirem vítimas de acidentes de trânsito há um predomínio das categorias: "de remoção da vítima estabilizada para o PS mais próximo" e "unido e em equipe", uma vez que cada uma, isoladamente, representa $41,66 \%$ das respostas. 
No que tange as opinióes dos socorristas sobre o trabalho desenvolvido por eles, não houve homogeneidade nas opinióes, haja vista que 50\% dos respondentes referem que o trabalho pode ser desenvolvido de outra forma e os outros $50 \%$ dizem que o trabalho não necessita ser desenvolvido de maneira diferente da atual.

Diante dos resultados obtidos, observa-se uma diversidade de percepçóes dos socorristas do APHM acerca do trabalho que desenvolvem com seus colegas quando assistem vítimas de acidentes de trânsito, que necessitam ser questionadas e repensadas como forma de entender por onde começar as mudanças no contexto de trabalho em equipe, nas instituiçóes de saúde, que desenvolvem o APHM.

É notório que o trabalho em equipe tem grande importância na esfera do atendimento pré-hospitalar, pois se o atendimento não fluir de uma forma adequada, todos saem perdendo: a vítima que precisa de atendimento hospitalar; a equipe que a atendeu no pré-hospitalar, pelo desgaste físico e emocional e a frustração de não ter conseguido chegar ao objetivo que é o de um bom atendimento; e a equipe que o receberá no hospital também será prejudicada, pois acaba se deparando com circunstâncias que poderiam ter sido minimizadas ou até evitadas [17].

\section{Conclusão}

O APHM pressupóe o domínio do trabalho em equipe, além da formação técnica ou acadêmica de cada profissional. É indubitável a relevância do atendimento às vítimas de acidentes de trânsito e o envolvimento de toda a equipe nesse processo de trabalho, necessitando assim de uma estruturação do serviço baseado na interdisciplinaridade. Há que se buscar uma forma de organização do trabalho, de gestão desse sistema, respeitando as especificidades nacionais e regionais, valorizando o campo cuidador, inerente a todos os trabalhadores.

\section{Referências}

1. Soerensen AA, Moriya TM, Soerensen R, Robazzi MLC. Atendimento pré-hospitalar móvel: fatores de riscos ocupacionais. Rev Enferm UERJ 2008;10218792.

2. Pereira WAP, Lima MAS. Atendimento pré-hospitalar: caracterizaçáo das ocorrências de acidente de trânsito. Acta Paul Enferm 2006;19(3):270-83.

3. Oliveira NLB, Souza RMC. Diagnóstico de lesôes e qualidade de vida de motociclistas, vítimas de acidentes de trânsito. Rev Latinoam Enfermagem 2003;11(6):749-56.

4. Pereira WAP, Lima MAS. O trabalho em equipe no atendimento pré-hospitalar à vítima de acidente de trânsito. Rev Esc Enferm USP 2009;43(2).

5. Marconi MA, Lakatos EM. Fundamentos de metodologia científica. 3a ed. São Paulo: Atlas; 1995.

6. Minayo MCS. O desafio do conhecimento: Pesquisa qualitativa em saúde. São Paulo: Hucitec; 1998.

7. Brasil. Resolução 196. Diretrizes e Normas Regulamentadoras de Pesquisas Envolvendo Seres Humanos. Brasília: Diário Oficial da República Federativa do Brasil; 1996.

8. Andrade ML, Caetano JA, Soares E. Percepção das enfermeiras sobre a unidade de emergência. Revista Rene 2000;1(1): 91-7.

9. Costa CE, Araújo L, Cardoso P, Zanata T. As características do suporte avançado de vida. Revista de trabalhos acadêmicos, América do Norte, jun.; 2010. [citado 2010 Out 29]. Disponível em: URL: http://revista. universo.edu.br

10. Pires D. A estrutura objetiva do trabalho em saúde. In: Leopardi MT. Processo de trabalho em saúde: organização e subjetividade. Florianópolis, Programa de Pós-graduaçáo em Enfermagem (UFSC): Papa-Livros; 1999. p. 25-48.

11. Leyser ME. Oficina de protocolos: etapas de elaboração passo a passo. Porto Alegre; 2007. [citado 2010 Out 27]. Disponível em: URL: http://www.portalcoren-rs. gov.br

12. Silveira ET, Moulin AFV. Socorros de Urgência em Atividades Físicas. Brasília: Cofen; 2003.

13. Souza EF. A atuação do Enfermeiro no resgate rodoviário. SOS Estradas; 2009. [citado 2011 Out 26]. Disponível em URL:http://www.estradas.com.br

14. Teixeira JAC. Comunicação em saúde Relação Técnicos de Saúde - Utentes. Lisboa: Instituto Superior de Psicologia Aplicada; 2001.

15. Azevedo TMVE, Silva MJP. Relacionamento Interpessoal no Atendimento Pré-hospitalar: uma revisão bibliográfica. Revista Nursing 2008;11(125):455-60.

16. Gonçalves SPG, Xavier AAP, Pilatti LA. Tomada de decisão no tratamento de emergências. Revista Produção Online (UFSC) 2007;7(7):97-108.

17. Fortes AFA, Pires AO, Alkimin TB. Atuação nas bases operacionais de atendimento pré-hospitalar: significados e sentimentos da equipe médica e de enfermagem. Enfermagem Brasil 2011;10(2):77-84. 